\title{
CARE OF PATIENT LYING WITH VARIED SUPINE ANGLES: A QUANTITATIVE PRESSURE EVALUATION
}

\section{ÎNGRIJIREA PACIENTILOR ÎN POZITIA DE DECUBIT DORSAL CU VARIATIA UNGHIULUI DE ÎNCLINATIE: EVALUAREA CANTITATIVĂ A PRESIUNII}

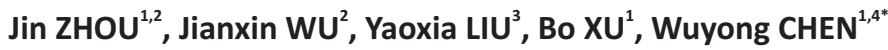 \\ ${ }^{1}$ National Engineering Laboratory for Clean Technology of Leather Manufacture, Sichuan University, Chengdu 610065, P. R. China \\ ${ }^{2}$ Science Lab, Zhejiang Red Dragonfly Footwear co., LTD, Wenzhou 325105, P. R. China \\ ${ }^{3}$ Sichuan Provincial People's Hospital, Chengdu 610000, P. R. China
}

${ }^{4}$ Key Laboratory for Leather Chemistry and Engineering of the Education Ministry, Sichuan University, Chengdu 610065, P. R. China

\begin{abstract}
CARE OF PATIENT LYING WITH VARIED SUPINE ANGLES: A QUANTITATIVE PRESSURE EVALUATION
ABSTRACT. The aim of this study was to clarify the pressure distribution of patient lying with varied supine angle on the standard hospital mattress (SHM) and sheep skin mattress (SSM), and then to compare the pressure relieving of those two kinds of mattresses which have been widely used in the pressure prevention. Eighteen healthy students were recruited from the university. Pressure distribution of SHM and SSM were measured by mFLEX measurement system in the supine angle of $0^{\circ}$, $30^{\circ}, 60^{\circ}$ and $90^{\circ}$. Pressure areas were divided into four parts: total, back, sacrum and heel area, under which peak pressure (PP) (mmHg), mean pressure (MP) $(\mathrm{mmHg})$ and contact area $(\mathrm{CA})\left(\mathrm{cm}^{2}\right)$ were calculated. One-way ANOVA shows that with the supine angle change from the level to the vertical status, PP and CA at sacrum area was increasing as well, but PP at sacrum was still high in the $90^{\circ}$ supine angle; further Paired T test records that majority PP values were proved to be significantly reduced by the usage of SSM in each supine angle, in contrast with the control group of standard hospital mattress and pressure reduction of MP was limited. Although positive outcomes were observed in each supine angle when the SSM was applied, further improvement of SSM in the aspect of shape was still required, such as a 3D structure was introduced to lower the higher pressure at the sacrum area.
\end{abstract}

KEY WORDS: bed sores; pressure ulcer; mattresses; nursing assessment; nursing care

ÎNGRIJIREA PACIENTILOR ÎN POZITIA DE DECUBIT DORSAL CU VARIATIA UNGHIULUI DE ÎNCLINATIE: EVALUAREA CANTITATIVĂ A PRESIUNII REZUMAT. Scopul acestui studiu a fost acela de a clarifica distribuţia presiunii la pacienţii aflaţi în poziţia decubit dorsal cu variaţia unghiului de înclinaţie pe o saltea de spital obişnuită (SHM) şi pe o saltea din blană de oaie (SSM), şi apoi de a compara reducerea presiunii cu ajutorul celor două tipuri de saltele care au fost utilizate pe larg la reducerea presiunii. S-au recrutat optsprezece studenţi sănătoşi de la universitate. S-a măsurat distribuţia presiunii utilizând SHM şi SSM cu sistemul de măsurare mFLEX la unghiurile de înclinaţie de $0^{\circ}, 30^{\circ}, 60^{\circ}$ şi $90^{\circ}$. Zonele de presiune au fost împărţite în patru părţi: zona totală, zona dorsală, zona sacrală şi zona călcâiului, pentru care s-au calculat presiunea maximă (PP) $(\mathrm{mmHg})$, presiunea medie (MP) $(\mathrm{mmHg})$ şi zona de contact $(\mathrm{CA})$ ( $\left.\mathrm{cm}^{2}\right)$. Analiza One-way ANOVA arată că, odată cu schimbarea unghiului de înclinaţie din poziţie orizontală în poziţie verticală, PP şi CA în zona sacrală au crescut, de asemenea, dar PP în zona sacrală a fost ridicată la un unghi de înclinaţie de $90^{\circ}$. În plus, testul t împerecheat a arătat că majoritatea valorilor PP s-au dovedit a fi semnificativ reduse prin utilizarea SSM la fiecare unghi de înclinaţie, spre deosebire de grupa martor care a utilizat salteaua de spital obişnuită, iar reducerea presiunii medii a fost limitată. Deși s-au observat rezultate pozitive la fiecare unghi de înclinaţie atunci când s-a utilizat SSM, sunt necesare în continuare îmbunătăţii în privinţa formei SSM, cum ar fi introducerea unei structuri 3D pentru a reduce presiunea ridicată din zona sacrală.

CUVINTE CHEIE: escare; ulcer de presiune; saltele; evaluarea îngrijirii medicale; îngrijire medicală

\section{SOINS DES PATIENTS EN DÉCUBITUS DORSAL EN VARIANT LES ANGLES D'INCLINAISON: L'ÉVALUATION QUANTITATIVE DE LA PRESSION}

RÉSUMÉ. Le but de cette étude a été de clarifier la répartition de pression chez les patients en décubitus dorsal avec la variation de l'angle d'inclinaison sur un matelas d'hôpital standard (SHM) et un matelas de peau de mouton (SSM), puis de comparer le soulagement de la pression en utilisant ces deux type de matelas qui ont été largement utilisés dans le soulagement de la pression. Dix-huit étudiants en bonne santé ont été recrutés de l'université. On a mesuré la distribution de la pression avec SHM et SSM par le système de mesure de mFLEX avec l'angle d'inclinaison de $0^{\circ}, 30^{\circ}, 60^{\circ}$ et $90^{\circ}$. Les zones de pression ont été divisées en quatre parties: la zone totale, la zone dorsale, la zone du sacrum et la zone du talon, pour lesquelles on a calculé la pression maximale (PP) ( $\mathrm{mmHg}$ ), la pression moyenne (MP) ( $\mathrm{mmHg}$ ) et la zone de contact $(\mathrm{CA})\left(\mathrm{cm}^{2}\right)$. L'analyse de variance montre que le changement de l'angle d'inclinaison de la position couchée à la position verticale, PP et CA dans la zone du sacrum ont augmenté, mais PP dans la zone du sacrum était encore haute à l'angle de $90^{\circ}$ en position couchée. En outre, le test T a révélé que la majorité des valeurs de PP ont été significativement réduites par l'utilisation de SSM dans chaque angle en position couchée, en contraste avec le groupe de matelas d'hôpital standard et la réduction de la pression de moyenne était limitée. Bien que des résultats positifs ont été observés dans chaque angle d'inclinaison Iorsqu'on a appliqué le SSM, une amélioration de SSM dans l'aspect de la forme est toujours nécessaire, par exemple une structure en 3D a été introduite pour abaisser la haute pression à la zone du sacrum.

MOTS CLÉS: escarres; ulcère de pression; matelas; évaluation des soins infirmiers; soins infirmiers

* Correspondence to: Wuyong CHEN, National Engineering Laboratory for Clean Technology of Leather Manufacture, Sichuan University Chengdu 610065, P. R. China, Phone number: 008613330945940. Fax: 86-28-85405237, email: wuyong.chen@163.com 


\section{INTRODUCTION}

Occurrence of pressure ulcer is always accompanied by a high pressure [1] and hampered vascular circulation $[2,3]$. According to the human structure, in the posture of supine lying, the protrusions of bone, such as scapula at back, sacrum of buttock and foot calcaneus, construct a plane to support the whole body weight [4], at which relatively higher contact pressures are usually observed. Particularly, the majority of the body mass is concentrated at the middle of the body in supine posture and the highest incidence of ulceration was found at the sacrum area $[5,6]$. Thereby the longterm hospitalized patients who suffered from immobility or disability were the high-risk groups [7] and advance interventions in the nursing stage appear to be crucial.

Scientific way to avoid the occurrence of ulcer is to lower the pressure and promote the circulation of vascular system. Currently, both the way of turnover and application of constant low pressure (CLP) system could achieve well ulcer prevention. In terms of CLP system, they were mainly classified into two groups [8, 9]: one was the Low-tech CLP, for instance the sheepskin mattress; another was alternative pressure air mattress (APAM) which was composed of large air units and it adjusted the contact area by the inflation or deflation of these units [10]. Purposely inflation or deflation of APAM shifted the centre of pressure and avoided the long time loading on the same place; whereas, APAM was expensive and it was proved not to be superior to the low-tech CLP in ulcer prevention [8]. Another easy way to solve the problem of pressure concentration is the approach of turnover. However this method becomes difficult when the patient has a heavy weight or the patient is sleeping at night. Similar with the above method, changing the supine angle could also transfer the centre of pressure and avoid pressure concentration; meanwhile varied supine angle made the patient convenient to have daily activities, such as eating and watching TV. Further, the pressure distribution in the varied supine angle of patient was not clear and the risk of those postures contributing to the occurrence of ulcer was still unknown.

\section{INTRODUCERE}

Apariţia ulcerului de presiune este întotdeauna însoţită de o presiune ridicată [1] şi de circulaţie sanguină îngreunată $[2,3]$. Conform structurii umane, în poziţia de decubit dorsal, proeminenţele osoase, cum ar fi omoplatul, osul sacru şi calcaneul, constituie o structură de sprijin pentru a susţine întreaga greutate corporală [4], la nivelul căreia se observă de obicei presiuni de contact relativ mai mari. Cea mai mare parte a masei corpului se concentrează în mod special la mijlocul corpului în poziţia de decubit dorsal, iar cea mai mare incidenţă de ulceraţii se întâlneşte în zona sacrală $[5,6]$. Astfel, pacienţii spitalizaţi pe termen lung care prezintă imobilitate sau handicap constituie grupele cu risc ridicat [7], iar intervenţiile preventive în etapa de îngrijire medicală par a fi cruciale.

Metoda ştiinţifică pentru evitarea apariţiei ulceraţiilor este de a reduce presiunea şi de a facilita circulaţia sistemului vascular. În prezent, ulceraţiile pot fi prevenite prin schimbarea poziţiei şi prin aplicarea sistemelor de presiune joasă constantă (CLP). În ceea ce priveşte sistemele CLP, acestea au fost clasificate în două grupe principale $[8,9]$ : una de nivel tehnologic scăzut, de exemplu, salteaua din blană de oaie; şi cealaltă reprezentată de o saltea cu presiune alternativă (APAM), compusă din celule mari pentru circulaţia aerului, cu ajustarea zonei de contact prin inflaţia sau deflaţia acestor celule [10]. Inflaţia sau deflaţia intenţionată a APAM duce la deplasarea centrului de presiune şi evită apăsarea unei zone timp îndelungat; însă sistemul APAM este scump şi s-a dovedit a fi inferior sistemului CLP de nivel tehnologic scăzut în prevenirea ulceraţiilor [8]. Un alt mod simplu de a rezolva problema concentrării presiunii este schimbarea poziţiei. Totuşi, această metodă devine dificilă atunci când pacientul are o greutate mare sau în timpul somnului. Similar metodei de mai sus, schimbarea unghiului de înclinaţie ar putea transfera, de asemenea, centrul de presiune şi ar putea evita concentrarea presiunii; în acelaşi timp, unghiul de înclinaţie variabil îi permite pacientului să desfăşoare activităţi de zi cu zi, precum luarea mesei şi privitul la televizor. Totuşi, distribuţia presiunii cu variaţia unghiului de înclinaţie nu este clară, iar riscul contribuţiei acelor poziţii la apariţia ulceraţiilor este necunoscut. 
Therefore, the aim of this study was to clarify the pressure distribution of patient lying with varied supine angle on the medical mattress and sheep skin mattress, and then to compare the pressure relieving of those two kinds of mattresses which have been widely used in the pressure prevention $[8,9]$.

\section{MATERIAL AND METHODS}

\section{Study Design}

This study was designed as a observational and case control study.

\section{Setting and Samples}

Experiments were carried out between September, 2013 and January, 2014 in the university's biomechanics laboratory. In the view point of safety, healthy subjects were recruited [11]. Eighteen healthy (11 males and 7 females) students aged between 20 and 27 were recruited from Sichuan University. The body weight and height were first measured and then body mass index (BMI) was calculated. Those students with BMI over 24.5 and with a history of back pain were excluded. The aims and methods were explained and participants have given their formal approvals prior to the measurement. All procedure of this study was supervised by ethic committees of Sichuan University and followed the principles of Declaration of Helsinki.

\section{Measurements and Instruments}

Four supine angles were selected in this study: $0^{\circ}$, $30^{\circ}, 60^{\circ}$, and $90^{\circ}$. Those angles were randomly arranged to each subject whilst pressure measurement and they were set manually by observer.

Two types of mattress were provided: a standard hospital mattress $(180 \times 90 \times 6 \mathrm{~cm}$, HuaZhiJie Ltd., Chengdu, China) (SHM) and it was composed of the foam and coir mat with the thickness of $3 \mathrm{~cm}$; a sheepskin mattress (SSM) $(180 \times 90 \times 5 \mathrm{~cm}$, ownfabricated, Chengdu, China) which was tanned under the guidelines of Australian Medical Sheepskin (Australian Standards: As4480.1) and the mean diameter of hair is $22.5 \mathrm{um}$, mean length is $26.3 \mathrm{~mm}$
Prin urmare, scopul acestui studiu a fost acela de a clarifica distribuţia presiunii la pacienţii în poziţia de decubit dorsal cu variaţia unghiului de înclinaţie, utilizând o saltea medicală şi o saltea din blană de oaie, şi apoi de a compara reducerea presiunii cu ajutorul celor două tipuri de saltele, care au fost utilizate pe scară largă la reducerea presiunii $[8,9]$.

\section{MATERIALE ŞI METODE}

\section{Designul studiului}

Acest studiu a fost conceput ca un studiu observaţional de tip „caz-control”.

\section{Cadru şi eşantion}

Studiul s-a desfăşurat în perioada septembrie 2013 ianuarie 2014, în laboratorul de biomecanică al universităţii Sichuan. Pentru siguranţă, s-au recrutat subiecţi sănătoşi [11]. Optsprezece studenţi sănătoşi (11 bărbaţi şi 7 femei) cu vârste cuprinse între 20 şi 27 de ani au fost recrutaţi de la Universitatea Sichuan. S-au măsurat mai întâi greutatea corporală şi înălţimea, apoi s-a calculat indicele de masă corporală (IMC). Studenţii cu IMC peste 24,5 şi care au prezentat dureri de spate în trecut au fost excluşi. Participanţilor li s-au explicat obiectivele şi metodele studiului şi aceştia şi-au dat aprobarea oficială înainte de efectuarea măsurătorilor. Toate procedurile din cadrul acestui studiu au fost supravegheate de comisiile de etică ale Universităţii Sichuan şi au urmat principiile Declaraţiei de la Helsinki.

\section{Măsurători şi instrumente}

În acest studiu s-au selectat patru unghiuri de înclinaţie: $0^{\circ}, 30^{\circ}, 60^{\circ}$ şi $90^{\circ}$. Aceste unghiuri au fost atribuite aleatoriu fiecărui subiect în timp ce s-a măsurat presiunea şi au fost setate manual de către observator.

S-au utilizat două tipuri de saltele: o saltea de spital obişnuită $(180 \times 90 \times 6 \mathrm{~cm}$, HuaZhiJie Ltd., Chengdu, China) (SHM), alcătuită din burete şi fibră din nucă de cocos, cu grosimea de $3 \mathrm{~cm}$; o saltea din blană de oaie (SSM) $(180 \times 90 \times 5 \mathrm{~cm}$, fabricaţie proprie, Chengdu, China), care a fost tăbăcită conform standardului australian privind blănurile de oaie de uz medical (Standard australian: As4480.1), cu diametrul mediu al firului de păr de $22,5 \mu \mathrm{m}$, lungimea medie de 
and density is $3095 / \mathrm{cm}^{2}$. Two groups were available and provided randomly for measurements: SHM and SSM.

The mFLEX pressure measuring system (mFLEX: 32 $x$ 32, Rsscan international, Belgium) was used to gain the contact pressure between the body and the mattress surface. The size of this system is $2100 \mathrm{~mm} \mathrm{x}$ $890 \mathrm{~mm} \times 4 \mathrm{~mm}$, the area of pressure sensors is 1920 $\mathrm{mm} \times 762 \mathrm{~mm}$, the number of sensors is 1024, the range of measure is $0-100 \mathrm{mmHg}(0-13 \mathrm{kPa})$ and the frequency is $5 \mathrm{~Hz}$. Calibration was made before measure. Four-mask model was available (Figure 1): total, back, sacrum and heel area. Pressure variables of the peak pressure (PP) $(\mathrm{mmHg})$, mean pressure (MP) $(\mathrm{mmHg})$ and contact area $(\mathrm{CA})\left(\mathrm{cm}^{2}\right)$ were gained for each region by the software of mFLEX (V4.0, Rsscan international, Belgium). Only one experienced observer was assigned to complete all the analysis to eliminate the inter-observer's error.
$26,3 \mathrm{~mm}$ şi densitatea de $3095 / \mathrm{cm}^{2}$. Acestea au constituit două grupe, SHM şi SSM, şi s-au utilizat aleatoriu pentru măsurători.

Sistemul de măsurare a presiunii mFLEX (mFLEX: $32 x$ 32, Rsscan International, Belgia) a fost utilizat pentru a obţine presiunea de contact dintre corp şi suprafaţa saltelei. Dimensiunea acestui sistem este de $2100 \mathrm{~mm}$ x $890 \mathrm{~mm} \times 4 \mathrm{~mm}$, aria de senzori de presiune este de 1920 $\mathrm{mm} \times 762 \mathrm{~mm}$, numărul de senzori este 1024, gama de măsurare este $0-100 \mathrm{mmHg}(0-13 \mathrm{kPa})$ şi frecvenţa de $5 \mathrm{~Hz}$. S-a făcut calibrarea înainte de măsurători. S-a utilizat un model cu patru zone (Figura 1): zona totală, zona dorsală, zona sacrală şi zona călcâiului. Pentru fiecare regiune s-au obţinut variabile precum presiunea maximă $(\mathrm{PP})(\mathrm{mmHg})$, presiunea medie (MP) $(\mathrm{mmHg})$ şi zona de contact (CA) $\left(\mathrm{cm}^{2}\right)$ cu ajutorul software-ului mFLEX (V4.0, Rsscan International, Belgia). Sarcina de a efectua toate analizele a fost repartizată unui singur observator cu experienţă, pentru a elimina eroarea inter-observator.

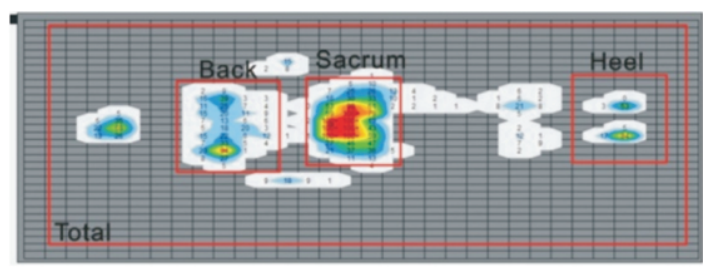

Figure 1. Four masks model of analysis

Figura 1. Modelul de analiză cu patru zone

\section{Data Collection and Procedure}

Participants were asked to wear their own leisure clothes; further a procedure of three to five minutes warm up was provided and made sure that each subject could adjust their own supine posture to be the natural and comfort one. When the subjects lay in the bed in supine posture without further moving and their plantar pressure became stable, the mFLEX system was switched on randomly by the researcher and then ten seconds data was recorded, within which 50 frames $(10 \mathrm{~s} \times 5 \mathrm{~Hz})$ of pressure distribution patterns have been saved. Thereby, the whole measuring process could not be aware by the subject and only one trial for each subject in one day measurement was enough for the data analysis. Only one measure was recorded for each mattress and for each subject. The same procedure was repeated for the supine angle of $0^{\circ}, 30^{\circ}, 60^{\circ}$, and $90^{\circ}$ randomly.

\section{Colectarea datelor şi procedură}

Participanţii au fost rugaţi să poarte haine comode; în plus s-a alocat o perioadă de încălzire de trei până la cinci minute şi s-a asigurat că fiecare subiect îşi poate ajusta postura în aşa fel încât să stea într-o poziţie naturală şi confortabilă. Atunci când presiunea plantară a subiecţilor întinşi pe pat în poziţia de decubit dorsal, fără a se mişca, a devenit stabilă, cercetătorul a pornit sistemul mFLEX la întâmplare şi s-au înregistrat zece secunde de date, în care s-au salvat 50 de cadre (10s x 5 $\mathrm{Hz}$ ) ale modelului de distribuţie a presiunii. Astfel, subiectul nu a putut fi conştient de procesul de măsurare în ansamblu şi pentru analiza datelor a fost suficient doar un test pentru fiecare subiect într-o singură zi. S-a înregistrat o singură măsurătoare pentru fiecare saltea şi pentru fiecare subiect. Aceeaşi procedură a fost repetată pentru unghiurile de înclinaţie $0^{\circ}, 30^{\circ}, 60^{\circ}$ şi $90^{\circ}$ aplicate în mod aleatoriu. 


\section{Data Analysis}

Fifty frames of pressure distribution from the ten seconds measurement was first averaged individually and then among the group of $0^{\circ}, 30^{\circ}$, $60^{\circ}, 90^{\circ}$; then the normal distribution was tested by Q-Q plot. Contact pressure with SHM and SSM in supine angle of $0^{\circ}, 30^{\circ}, 60^{\circ}$ and $90^{\circ}$ were compared by Paired-T test individually and One-way ANOVA with LSD was used for exploring the variation between the supine angles. All statistical analysis was operated in the software of SPSS (V16.0, SPSS Inc, USA) with significant level of 0.05 and confidence interval of $95 \%$.

\section{RESULTS}

Mean age of the students is $24.2 \pm 1.7 \mathrm{yrs}$, mean height is $167.9 \pm 8.2 \mathrm{~cm}$, mean body weight is $58.8 \pm 7.7 \mathrm{~kg}$ and mean $\mathrm{BMI}$ is $20.8 \pm 1.4$. All obtained data in supine posture followed the normal distribution.

\section{Compare within Varied Supine Angle of SHM and SSM}

With the supine angle changed from $0^{\circ}$ to $90^{\circ}$, contact pressure gradually shifts from the waist to the sacrum, in which it caused the significant differences between varied supine angles (Table 1 ). In terms of SHM, variable of MP of $0^{\circ}$ was significantly lower than those of $60^{\circ}(p=0.005)$ and $90^{\circ}(p=0.000)$. Further MP at $30^{\circ}(p=0.01)$ and $60^{\circ}(p=0.005)$ were also significantly smaller than those of $90^{\circ}$. Similar tendency of MP at buttock and heel areas and no significant change happened on the region of back, as the supine angle increasing.

In terms of SSM, at the sacrum area (Figure 2), PP at $0^{\circ}$ was significantly smaller than that of $30^{\circ}$ by 5.6 $\mathrm{mmHg}(p=0.0010)$; whereas, $\mathrm{PP}$ and MP was significantly lower than that of $60^{\circ}$ by 6.2 and 7.0 $\mathrm{mmHg}(\mathrm{p}=0.001$ for PP; $\mathrm{p}=0.021$ for $\mathrm{MP})$, respectively. Similar result was obtained between $0^{\circ}$ and $90^{\circ}$, where, $\mathrm{PP}$ and $\mathrm{MP}$ at $0^{\circ}$ were significant smaller than $90^{\circ}$ by 6.2 and $10.2 \mathrm{mmHg}(p=0.001$ for $P P ; p=0.000$ for MP). No significant differences were found at other regions whilst supine angle increasing.

\section{Analiza datelor}

S-a făcut media a cincizeci de cadre de distribuţie a presiunii din măsurătoarea de zece secunde, mai întâi individual şi apoi pe grupe, în funcţie de unghi: $0^{\circ}, 30^{\circ}, 60^{\circ}$, $90^{\circ}$; apoi s-a testat distribuţia normală prin reprezentarea grafică Q-Q. S-au comparat individual presiunile de contact la utilizarea SHM şi SSM la unghiurile de înclinaţie de $0^{\circ}$, $30^{\circ}, 60^{\circ}$ şi $90^{\circ}$, cu ajutorul testului tîmperecheat, iar analiza One-way ANOVA cu LSD s-a utilizat pentru a explora variaţia dintre unghiurile de înclinaţie. Toate analizele statistice au fost efectuate cu programul SPSS (V16.0, SPSS Inc., SUA) cu nivel de semnificaţie de 0,05 şi intervalul de încredere de $95 \%$.

\section{REZULTATE}

Vârsta medie a studenţilor a fost de $24,2 \pm 1,7$ ani, înălţimea medie a fost de $167,9 \pm 8,2 \mathrm{~cm}$, greutatea medie a fost $58,8 \pm 7,7 \mathrm{~kg}$, iar IMC mediu a fost $20,8 \pm$ 1,4 . Toate datele obţinute din poziţia de decubit dorsal s-au încadrat în distribuţia normală.

\section{Comparaţia unghiurilor de înclinaţie ale SHM şi SSM}

Odată cu schimbarea unghiului de înclinaţie de la $0^{\circ}$ la $90^{\circ}$, presiunea de contact se deplasează treptat de la talie la osul sacru, dând naştere unor diferenţe semnificative între unghiurile de înclinaţie variate (Tabelul 1). În ceea ce priveşte SHM, variabila MP la $0^{\circ}$ a fost semnificativ mai mică decât MP la $60^{\circ}(p=0,005)$ şi $90^{\circ}(p=0,000)$. În plus, valorile MP la $30^{\circ}(p=0,01)$ şi $60^{\circ}$ $(p=0,005)$ au fost, de asemenea, semnificativ mai mici decât cele ale MP la $90^{\circ}$. S-a observat o tendinţă similară a MP în zona feselor şi în zona călcâiului şi nu a avut loc nicio schimbare semnificativă în regiunea dorsală, pe măsură ce unghiul de înclinaţie a crescut.

în ceea ce priveşte SSM, în zona sacrală (Figura 2), valoarea PP la $0^{\circ}$ a fost semnificativ mai mică decât cea la $30^{\circ} \mathrm{cu} 5,6 \mathrm{mmHg}(p=0,0010)$; PP şi MP au fost semnificativ mai mici decât cele la $60^{\circ} \mathrm{cu} 6,2$, respectiv $7,0 \mathrm{mmHg}$ ( $p=0.001$ pentru PP; $p=0.021$ pentru MP). Rezultate similare au fost obţinute între $0^{\circ}$ şi $90^{\circ}$, PP şi $\mathrm{MP} \mathrm{la} 0^{\circ}$ fiind semnificativ mai mici decât la $90^{\circ} \mathrm{cu} 6,2$ şi $10,2 \mathrm{mmHg}$ ( $p=0,001$ pentru PP; $p=0,000$ pentru MP). Nu s-au observat diferenţe semnificative în alte regiuni la creşterea unghiului de înclinaţie. 


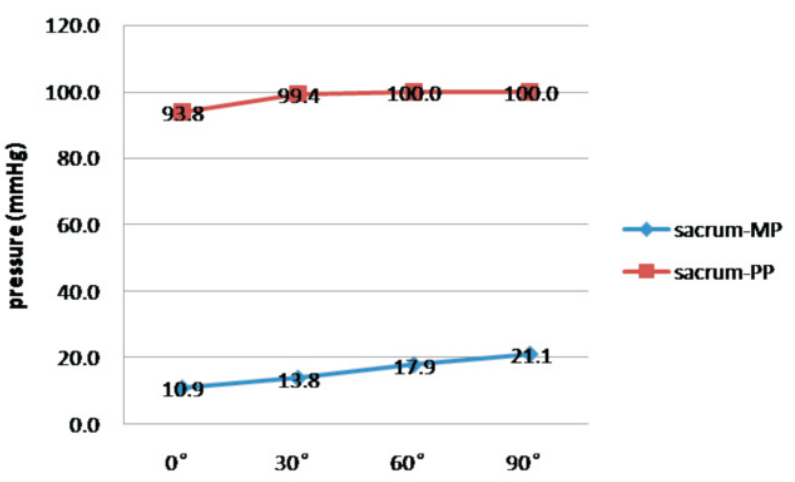

Figure 2. Changes of mean pressure and peak pressure with the supine angle at sacrum area of SSM

Figura 2. Modificarea presiunii medii şi a celei maxime în funcţie de unghiul de înclinaţie în zona sacrală a SSM

\section{Compare between the SHM and SSM in Each Supine Angle}

Generally, contact pressure of SSM group was ameliorated and this phenomenon was seen in each supine angle (Table 1 ). When subject was lying in $0^{\circ}$, in total area, PP of SSM lowered from $98.3 \mathrm{mmHg}$ to 93.8 $\mathrm{mmHg}$; while that of MP decreased by $0.2 \mathrm{mmHg}$ from $2.7 \mathrm{mmHg}$ and this declination was not significant. At the back area, the SSM significantly attenuated the PP and MP by $16.4 \mathrm{mmHg}(\mathrm{p}=0.000)$ (Figure 3 ) and 1.0 $\mathrm{mmHg}(p=0.008)$ (Figure 4$)$, respectively. The same phenomenon was found at the PP of sacrum, where 5.6 $\mathrm{mmHg}(p=0.024)$ PP was diminished by the usage of SSM.

\section{Comparaţie între SHM şi SSM la fiecare unghi de înclinaţie}

În general, presiunea de contact a grupei SSM s-a ameliorat şi acest fenomen a fost observat la fiecare unghi de înclinaţie (Tabelul 1). Când subiectul a stat în poziţie culcată la $0^{\circ}$, PP la utilizarea SSM a scăzut de la 98,3 mmHg la 93,8 mmHg în zona totală, în timp ce MP a scăzut cu $0,2 \mathrm{mmHg}$ de la $2,7 \mathrm{mmHg}$, dar această scădere nu a fost semnificativă. În zona dorsală, SSM a atenuat semnificativ PP şi MP cu $16,4 \mathrm{mmHg}(p=0.000)$ (Figura 3), respectiv $1,0 \mathrm{mmHg}(p=0,008)$ (Figura 4). Acelaşi fenomen a fost observat la PP în zona sacrală, unde PP a scăzut cu 5,6 mmHg $(p=0.024)$ la utilizarea SSM.

Table 1: Paired T-test of contact pressure distribution of SHM and SSM Tabelul 1: Testul t împerecheat al distribuţiei presiunii de contact la grupele SHM şi SSM

\begin{tabular}{|c|c|c|c|c|c|c|c|}
\hline $\begin{array}{c}\text { Region } \\
\text { Zonă }\end{array}$ & $\begin{array}{c}\text { Mattress } \\
\text { Saltea }\end{array}$ & $\begin{array}{c}\text { Angle } \\
\text { Unghi }\end{array}$ & $\begin{array}{c}\text { Number } \\
\text { Număr }\end{array}$ & SHM & SSM & $\begin{array}{c}\text { Differences } \\
\text { Diferenţe }\end{array}$ & Sig \\
\hline $\begin{array}{c}\text { Total } \\
\text { Totală }\end{array}$ & $\begin{array}{c}\text { PP } \\
(\mathrm{mmHg})\end{array}$ & $0^{\circ}$ & 18 & 98.27 & 93.79 & 4.48 & 0.082 \\
\hline $\begin{array}{c}\text { Total } \\
\text { Totală }\end{array}$ & $30^{\circ}$ & 18 & 100.00 & 99.39 & 0.61 & 0.331 \\
\hline $\begin{array}{c}\text { Total } \\
\text { Totală }\end{array}$ & $60^{\circ}$ & 18 & 98.88 & 100.00 & -1.12 & 0.331 \\
\hline $\begin{array}{c}\text { Total } \\
\text { Totală }\end{array}$ & $90^{\circ}$ & 18 & 100.00 & 100.00 & 0.00 & 1.000 \\
\hline $\begin{array}{c}\text { Total } \\
\text { Totală }\end{array}$ & $\begin{array}{c}\mathrm{MP} \\
(\mathrm{mmHg})\end{array}$ & $0^{\circ}$ & 18 & 2.65 & 2.50 & 0.15 & 0.091 \\
\hline $\begin{array}{c}\text { Total } \\
\text { Totală }\end{array}$ & & $30^{\circ}$ & 18 & 3.03 & 3.25 & -0.22 & $0.011^{*}$ \\
\hline
\end{tabular}


Table 1: Continued

Tabelul 1: Continuare

\begin{tabular}{|c|c|c|c|c|c|c|c|}
\hline $\begin{array}{l}\text { Region } \\
\text { Zonă }\end{array}$ & $\begin{array}{l}\text { Mattress } \\
\text { Saltea }\end{array}$ & $\begin{array}{l}\text { Angle } \\
\text { Unghi }\end{array}$ & $\begin{array}{l}\text { Number } \\
\text { Număr }\end{array}$ & SHM & SSM & $\begin{array}{l}\text { Differences } \\
\text { Diferenţe }\end{array}$ & Sig \\
\hline $\begin{array}{l}\text { Total } \\
\text { Totală }\end{array}$ & & $60^{\circ}$ & 18 & 3.37 & 4.07 & -0.70 & $0.000 * *$ \\
\hline $\begin{array}{l}\text { Total } \\
\text { Totală }\end{array}$ & & $90^{\circ}$ & 18 & 3.70 & 4.45 & -0.75 & $0.000 * *$ \\
\hline $\begin{array}{l}\text { Total } \\
\text { Totală }\end{array}$ & $\begin{array}{c}\mathrm{CA} \\
\left(\mathrm{cm}^{2}\right)\end{array}$ & $0^{\circ}$ & 18 & 13000.00 & 12200.00 & 800.00 & 0.332 \\
\hline $\begin{array}{l}\text { Total } \\
\text { Totală }\end{array}$ & & $30^{\circ}$ & 18 & 13000.00 & 12200.00 & 800.00 & 0.332 \\
\hline $\begin{array}{l}\text { Total } \\
\text { Totală }\end{array}$ & & $60^{\circ}$ & 18 & 13000.00 & 13000.00 & 0.00 & 1.000 \\
\hline $\begin{array}{l}\text { Total } \\
\text { Totală }\end{array}$ & & $90^{\circ}$ & 18 & 13000.00 & 13000.00 & 0.00 & 1.000 \\
\hline $\begin{array}{c}\text { Back } \\
\text { Dorsală }\end{array}$ & PP & $0^{\circ}$ & 18 & 45.09 & 28.67 & 16.42 & $0.000 * *$ \\
\hline $\begin{array}{c}\text { Back } \\
\text { Dorsală }\end{array}$ & & $30^{\circ}$ & 18 & 40.65 & 27.99 & 12.66 & $0.005^{*}$ \\
\hline $\begin{array}{c}\text { Back } \\
\text { Dorsală }\end{array}$ & & $60^{\circ}$ & 18 & 41.92 & 30.35 & 11.57 & $0.003 *$ \\
\hline $\begin{array}{c}\text { Back } \\
\text { Dorsală }\end{array}$ & & $90^{\circ}$ & 18 & 46.63 & 30.63 & 16.00 & $0.001 *$ \\
\hline $\begin{array}{c}\text { Back } \\
\text { Dorsală }\end{array}$ & MP & $0^{\circ}$ & 18 & 5.42 & 4.35 & 1.07 & $0.008^{*}$ \\
\hline $\begin{array}{c}\text { Back } \\
\text { Dorsală }\end{array}$ & & $30^{\circ}$ & 18 & 4.69 & 4.15 & 0.54 & 0.159 \\
\hline $\begin{array}{c}\text { Back } \\
\text { Dorsală }\end{array}$ & & $60^{\circ}$ & 18 & 4.31 & 3.76 & 0.55 & 0.177 \\
\hline $\begin{array}{c}\text { Back } \\
\text { Dorsală }\end{array}$ & & $90^{\circ}$ & 18 & 4.28 & 3.91 & 0.37 & 0.339 \\
\hline $\begin{array}{c}\text { Back } \\
\text { Dorsală }\end{array}$ & CA & $0^{\circ}$ & 18 & 1342.27 & 1440 & -97.73 & 0.187 \\
\hline $\begin{array}{c}\text { Back } \\
\text { Dorsală }\end{array}$ & & $30^{\circ}$ & 18 & 1385.16 & 1457.58 & -72.42 & 0.398 \\
\hline $\begin{array}{c}\text { Back } \\
\text { Dorsală }\end{array}$ & & $60^{\circ}$ & 18 & 1435.08 & 1486.41 & -51.33 & 0.560 \\
\hline $\begin{array}{c}\text { Back } \\
\text { Dorsală }\end{array}$ & & $90^{\circ}$ & 18 & 1383.05 & 1383.75 & -0.70 & 0.993 \\
\hline $\begin{array}{l}\text { Sacrum } \\
\text { Sacrală }\end{array}$ & PP & $0^{\circ}$ & 18 & 99.44 & 93.80 & 5.64 & $0.024 *$ \\
\hline $\begin{array}{l}\text { Sacrum } \\
\text { Sacrală }\end{array}$ & & $30^{\circ}$ & 18 & 100.00 & 99.39 & 0.61 & 0.331 \\
\hline $\begin{array}{l}\text { Sacrum } \\
\text { Sacrală }\end{array}$ & & $60^{\circ}$ & 18 & 98.88 & 100.00 & -1.12 & 1.000 \\
\hline
\end{tabular}


Table 1: Continued

Tabelul 1: Continuare

\begin{tabular}{|c|c|c|c|c|c|c|c|}
\hline $\begin{array}{l}\text { Region } \\
\text { Zonă }\end{array}$ & $\begin{array}{l}\text { Mattress } \\
\text { Saltea }\end{array}$ & $\begin{array}{l}\text { Angle } \\
\text { Unghi }\end{array}$ & $\begin{array}{l}\text { Number } \\
\text { Număr }\end{array}$ & SHM & SSM & $\begin{array}{l}\text { Differences } \\
\text { Diferenţe }\end{array}$ & Sig \\
\hline $\begin{array}{l}\text { Sacrum } \\
\text { Sacrală }\end{array}$ & & $90^{\circ}$ & 18 & 100.00 & 100.00 & 0.00 & 1.000 \\
\hline $\begin{array}{l}\text { Sacrum } \\
\text { Sacrală }\end{array}$ & $\mathrm{MP}$ & $0^{\circ}$ & 18 & 11.44 & 10.90 & 0.54 & 0.380 \\
\hline $\begin{array}{l}\text { Sacrum } \\
\text { Sacrală }\end{array}$ & & $30^{\circ}$ & 18 & 13.23 & 13.83 & -0.60 & 0.484 \\
\hline $\begin{array}{l}\text { Sacrum } \\
\text { Sacrală }\end{array}$ & & $60^{\circ}$ & 18 & 15.98 & 17.89 & -1.91 & $0.041 *$ \\
\hline $\begin{array}{l}\text { Sacrum } \\
\text { Sacrală }\end{array}$ & & $90^{\circ}$ & 18 & 18.87 & 21.06 & -2.19 & 0.580 \\
\hline $\begin{array}{l}\text { Sacrum } \\
\text { Sacrală }\end{array}$ & $\mathrm{CA}$ & $0^{\circ}$ & 18 & 1847.11 & 1997.58 & -150.47 & 0.129 \\
\hline $\begin{array}{l}\text { Sacrum } \\
\text { Sacrală }\end{array}$ & & $30^{\circ}$ & 18 & 1968.05 & 2199.38 & -231.33 & 0.051 \\
\hline $\begin{array}{l}\text { Sacrum } \\
\text { Sacrală }\end{array}$ & & $60^{\circ}$ & 18 & 1897.06 & 2316.09 & -419.03 & $0.004 *$ \\
\hline $\begin{array}{l}\text { Sacrum } \\
\text { Sacrală }\end{array}$ & & $90^{\circ}$ & 18 & 1922.34 & 2234.53 & -312.19 & $0.009 *$ \\
\hline $\begin{array}{l}\text { Heel } \\
\text { Călcâi }\end{array}$ & PP & $0^{\circ}$ & 18 & 67.82 & 49.44 & 18.38 & 0.068 \\
\hline $\begin{array}{l}\text { Heel } \\
\text { Călcâi }\end{array}$ & & $30^{\circ}$ & 18 & 77.84 & 57.49 & 20.35 & $0.043 *$ \\
\hline $\begin{array}{l}\text { Heel } \\
\text { Călcâi }\end{array}$ & & $60^{\circ}$ & 18 & 76.75 & 60.92 & 15.83 & 0.099 \\
\hline $\begin{array}{l}\text { Heel } \\
\text { Călcâi }\end{array}$ & & $90^{\circ}$ & 18 & 80.18 & 63.02 & 17.16 & 0.090 \\
\hline $\begin{array}{l}\text { Heel } \\
\text { Călcâi }\end{array}$ & $\mathrm{MP}$ & $0^{\circ}$ & 18 & 3.08 & 2.88 & 0.20 & 0.727 \\
\hline $\begin{array}{l}\text { Heel } \\
\text { Călcâi }\end{array}$ & & $30^{\circ}$ & 18 & 3.49 & 5.44 & -1.95 & 0.374 \\
\hline $\begin{array}{l}\text { Heel } \\
\text { Călcâi }\end{array}$ & & $60^{\circ}$ & 18 & 4.02 & 3.84 & 0.18 & 0.732 \\
\hline $\begin{array}{l}\text { Heel } \\
\text { Călcâi }\end{array}$ & & $90^{\circ}$ & 18 & 4.97 & 4.19 & 0.78 & 0.112 \\
\hline $\begin{array}{l}\text { Heel } \\
\text { Călcâi }\end{array}$ & $\mathrm{CA}$ & $0^{\circ}$ & 18 & 727.74 & 704.53 & 23.21 & 0.711 \\
\hline $\begin{array}{l}\text { Heel } \\
\text { Călcâi }\end{array}$ & & $30^{\circ}$ & 18 & 755.16 & 628.91 & 126.25 & $0.039 *$ \\
\hline $\begin{array}{l}\text { Heel } \\
\text { Călcâi }\end{array}$ & & $60^{\circ}$ & 18 & 707.34 & 625.08 & 82.26 & $0.023^{*}$ \\
\hline $\begin{array}{l}\text { Heel } \\
\text { Călcâi }\end{array}$ & & $90^{\circ}$ & 18 & 680.46 & 587.11 & 93.35 & $0.010 *$ \\
\hline
\end{tabular}

* significant differences less than $0.05 ; * *$ significant differences less than 0.001

* diferenţe semnificative mai mici de 0,05; ** diferenţe semnificative mai mici de 0,001 


\section{Back area}

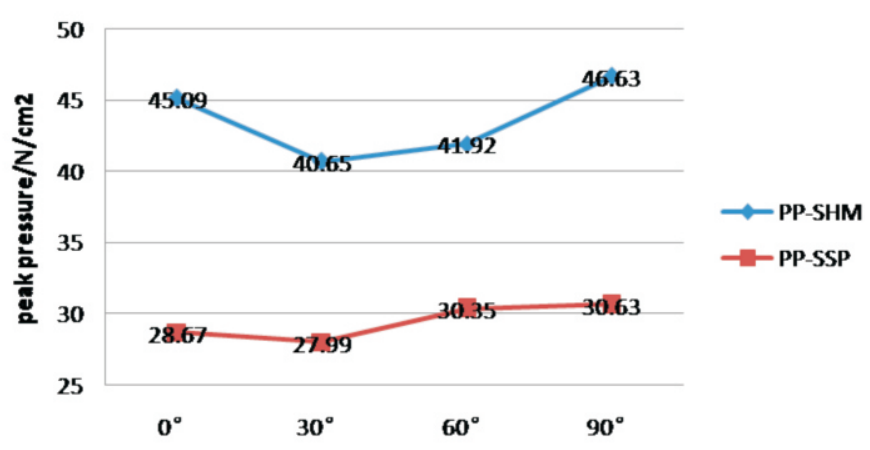

Figure 3. Changes of peak pressure with the supine angle at back area of SHM and SSM groups

Figura 3. Modificarea presiunii maxime în funcţie de unghiul de înclinaţie în zona dorsală la grupele SHM şi SSM

\section{back area}

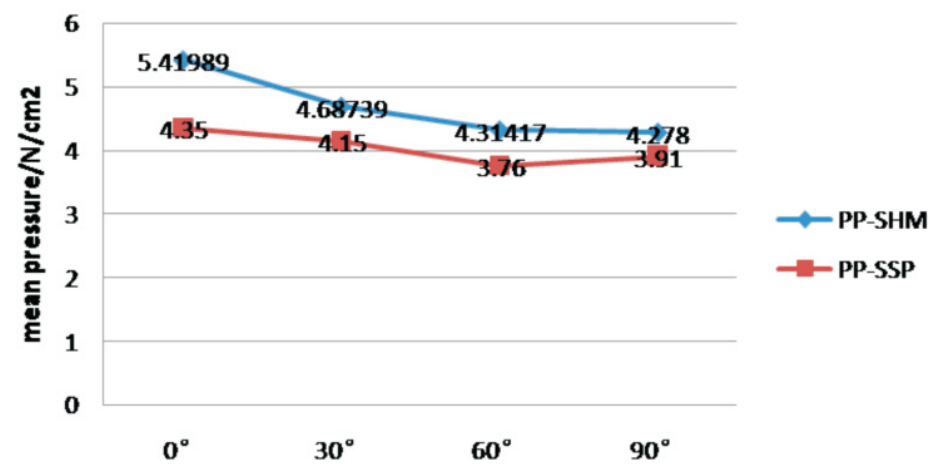

Figure 4. Changes of mean pressure with the supine angle at back area of SHM and SSM groups

Figura 4. Modificarea presiunii medii în funcţie de unghiul de înclinaţie în zona dorsală la grupele SHM şi SSM

In the supine angle of $30^{\circ}$, with the exception of MP at total area, where SHM group received a smaller pressure value by $0.3 \mathrm{mmHg}(p=0.011)$, other regions and variables approved that usage of SSM promoted the PP at the back and heel region, where $12.7 \mathrm{mmHg}$ $(p=0.005)$ (Figure 3$)$ and $20.3 \mathrm{mmHg}(p=0.043)$ (Table 1$)$ reductions were obtained individually.

When subject was lying in $60^{\circ}$, significant pressure reductions were found at back area (Figure 3) and significant contact area increasing was obtained at sacrum (Table 1), where $11.5 \mathrm{mmHg}(p=0.003)$ decreasing of PP and $419.0 \mathrm{~cm}^{2}(p=0.004)$ augment of CA were found.

In the supine angle of $90^{\circ}$, equaling to the sitting posture, except the PP at back area, where a significant pressure reduction was obtained by the application of SSM ( $p=0.001$ ) (Figure 3), no significant changes were found between group of SHM and SSM.
La unghiul de înclinaţie de $30^{\circ}$, cu excepţia MP în zona totală, unde grupa SHM a obţinut o valoare mai mică a presiunii cu $0,3 \mathrm{mmHg}(p=0,011)$, alte zone şi variabile au confirmat că utilizarea SSM favorizează PP în zona dorsală şi în zona călcâiului, unde $s$-au obţinut scăderi individuale de $12,7 \mathrm{mmHg}(p=0,005)$ (Figura 3) şi 20,3mmHg $(p=0,043)$ (Tabelul 1).

Când subiectul a stat în poziţie culcată la $60^{\circ}$, s-au constatat reduceri semnificative ale presiunii în zona dorsală (Figura 3), iar zona de contact a crescut semnificativ în zona osului sacru (Tabelul 1 ), unde s-au observat o scădere a PP cu $11,5 \mathrm{mmHg}(p=0,003)$ şi o creştere a CA cu $419,0 \mathrm{~cm}^{2}(p=0,004)$.

La unghiul de înclinaţie de $90^{\circ}$, specifică poziţiei în şezut, cu excepţia PP în zona dorsală, unde s-a obţinut o reducere semnificativă a presiunii prin aplicarea SSM ( $p$ $=0,001$ ) (Figura 3), nu s-a găsit nicio diferenţă semnificativă între grupele SHM şi SSM. 


\section{DISCUSSIONS}

In this study, contact pressure of healthy subjects lying on the SHM and SSM with the supine angle of $0^{\circ}$, $30^{\circ}, 60^{\circ}$ and $90^{\circ}$ were measured and then the comparison was made between SHM and SSM in pressure relieving. Our results show that with the supine angle change from the level to the vertical status, PP and CA at sacrum area was increasing as well, but PP at sacrum was still high in the $90^{\circ}$ supine angle; further, majority PP values were proved to be significantly reduced by the usage of SSM in each supine angle, in contrast with the control group of standard hospital mattress and pressure reduction of MP was limited.

In terms of varied supine angles, Defloor [3] studied the relationship between the contact pressure and supine angle and they concluded that lateral lying with $30^{\circ}$ supine angle showed the lowest total contact pressure, while that of $90^{\circ}$ supine angle was the largest. In our outcomes, we found that PP and MP of both SHM and SSM were increasing with the bed becoming vertical, particular at the angle higher than $60^{\circ}$. Thereby, the patient should be caution that the supine angle should not be higher than $60^{\circ}$ too long time, in case of pressure concentration on the sacrum and buttock area causes the occurrence of ulceration.

In terms of SSM, according to the clinical trial and pressure measure in literatures, McGowan et al. [8] recruited 297 post-operated patients who were prescribed with the sheepskin mattress during their nursing period and their outcomes showed that the mattress significantly reduced the incidence of ulceration ( $R R=0.30,95 \%$ confident interval: 0.17 to 0.52). Similarly, Jolley et al. [9] described that incidence of ulcer of traditional nursing approach was $9 \%(20 / 223)$, while it decreased to $5.5 \%$ $(12 / 218)$ ( $R R=0.58,95 \%$ confident interval: 0.35 to 0.96) after the intervention of the sheepskin mattress. Thereby SSM was considered as a good product for pressure reliving and for ulcer prevention. In terms pressure measurement, Jin et al. [11] used the pressure sensor to measure the contact pressure and their results approved the finding of McGowan and Jolley.

\section{DISCUTII}

În acest studiu s-a măsurat presiunea de contact la subiecţi sănătoşi în poziţie culcată pe saltelele SHM şi SSM la unghiurile de înclinaţie de $0^{\circ}, 30^{\circ}, 60^{\circ}$ şi $90^{\circ}$ şi apoi s-a făcut o comparaţie între SHM şi SSM în ceea ce priveşte reducerea presiunii. Rezultatele noastre arată că, odată cu schimbarea unghiului de înclinaţie din poziţie orizontală în poziţie verticală, PP şi CA în zona sacrală cresc, dar PP în zona sacrală este încă ridicată la unghiul de $90^{\circ}$; în plus, majoritatea valorilor PP s-au dovedit a fi reduse semnificativ prin utilizarea SSM la fiecare unghi de înclinaţie, în contrast cu grupa martor, în care s-a utilizat o saltea de spital obişnuită, iar reducerea presiunii medii a fost limitată.

În ceea ce priveşte unghiurile de înclinaţie variate, Defloor [3] a studiat relaţia dintre presiunea de contact şi unghiul de înclinaţie şi a ajuns la concluzia că cea mai mică presiune de contact totală se obţine în poziţia de decubit lateral la un unghi de $30^{\circ}$, în timp ce la unghiul de $90^{\circ} \mathrm{s}$-a obţinut cea mai mare valoare. În rezultatele noastre am constatat că, atât la utilizarea SHM, cât şi a SSM, PP şi MP au crescut odată cu ridicarea patului, în special la unghiuri mai mari de $60^{\circ}$. Astfel, pacientul trebuie să fie atenţionat că unghiul de înclinaţie nu trebuie să fie menţinut prea mult timp la o valoare mai mare de $60^{\circ}$, altfel concentrarea presiunii în zona sacrală şi în zona feselor determină apariţia ulceraţiei.

În ceea ce priveşte SSM, potrivit studiului clinic şi măsurătorilor de presiune din literatura de specialitate, McGowan şi colab. [8] au recrutat 297 de pacienţi cărora li s-a prescris utilizarea unei saltele din blană de oaie în perioada de îngrijire medicală postoperatorie şi rezultatele lor au arătat că salteaua a redus semnificativ incidenţa ulceraţiilor $(R R=0,30$, 95\% interval de încredere: de la 0,17 la 0,52). În mod similar, Jolley şi colab. [9] au descris că incidenţa ulceraţiilor în abordarea tradiţională a îngrijirii medicale a fost de $9 \%(20 / 223)$, scăzând la 5,5\% $(12 / 218)(R R=0.58,95 \%$ interval de încredere: de la 0,35 la 0,96) după utilizarea saltelei din blană de oaie. Astfel, SSM a fost considerat un produs bun pentru reducerea presiunii şi prevenirea ulceraţiilor. În ceea ce priveşte măsurarea presiunii, Jin şi colab. [11] au folosit senzorul de presiune pentru a măsura presiunea de contact, iar rezultatele lor au confirmat rezultatele obb̧inute de McGowan şi Jolley. 
As a classic CLP product, when the subject lies in the surface of SSM, the long and high density hair surface could be easily bended to match the shape of the loading surface and a much larger contact area could be built to support the body weight, so as to reduce the magnitude of pressure. Further, even though the surface of SSM is tightly pressed, minor gaps still exist within hairs and those spaces make the air circulation available. Therefore, the SSM is helpful for either avoiding the occurrence of ulcer or promoting the healing of ulceration. Our results in this study displayed that after the intervention of the SSM, the pressure distribution was ameliorated in each supine angle. Particularly at the back area, PP decreased significantly whilst lying upon SSM, where $16.4,12.7,11.5$ and $16.0 \mathrm{mmHg}$ reductions were found at the supine angle of $0^{\circ}, 30^{\circ}, 60^{\circ}$ and $90^{\circ}$ individually.

Although positive outcomes were obtained, several limitations should be considered whilst interpreting the results. Firstly, the samples size was small and the outcomes performed by those healthy subjects in our experimental study should not be generalized to other population. Since anthropological variations would result the significant differences in contact pressure, for instance the elder population would receive a lower peak pressure at sacrum area. Secondly, some PP exceeded the maximum rang (100 $\mathrm{mmHg}$ ) of the measuring system, but the part of pressure higher than $100 \mathrm{mmHg}$ was meaningless, as the capillary circulation have already been cut off when the pressure passed $10 \mathrm{kPa}(76 \mathrm{mmHg}$ ) [12]. Investigations still need to be done to further explore the correlation between effectiveness of the sheepskin mattress and the nature of sheep skin tanning technology.

\section{CONCLUSIONS}

Patient should be caution that the supine angle should not be higher than $60^{\circ}$ too long time, since in this angle, pressure is still high at sacrum and buttock area. Pressure relieve of sheep skin at each supine angle was quantitatively evaluated and it performed superior than the standard hospital mattress in the most of supine angles. However, further improvement of SSM in the aspect of shape
Ca produs clasic de tip CLP, atunci când subiectul stă întins pe suprafaţa saltelei SSM, părul lung şi foarte dens al blănii poate fi uşor îndoit pentru a lua forma suprafeţei de încărcare şi se poate construi o suprafaţă de contact mult mai mare pentru a sprijini greutatea corporală, astfel încât să se reducă amploarea presiunii. Mai mult, chiar dacă suprafaţa SSM este presată strâns, există mici goluri între fire, acele spaţii făcând posibilă circulaţia aerului. De aceea, SSM este utilă pentru evitarea apariţiei ulceraţiilor sau pentru facilitarea vindecării acestora. Rezultatele noastre din acest studiu au arătat că după utilizarea SSM, distribuţia presiunii a fost ameliorată în fiecare unghi de înclinaţie. În special în zona dorsală, PP a scăzut semnificativ în timpul utilizării SSM, observându-se scăderi cu 16,4, $12,7,11,5$ şi $16,0 \mathrm{mmHg}$ la unghiurile de înclinaţie de $0^{\circ}$, $30^{\circ}, 60^{\circ}$ şi $90^{\circ}$ individual.

Deşi s-au obţinut rezultate pozitive, la interpretarea rezultatelor ar trebui să luăm în considerare câteva limitări. În primul rând, eşantionul a fost mic şi rezultatele obţinute de aceşti subiecţi sănătoşi în studiul nostru experimental nu ar trebui să fie generalizate la alte populaţii. Întrucât variaţiile antropologice ar avea ca rezultat diferenţe semnificative ale presiunii de contact, de exemplu, la populaţia în vârstă s-ar constata o presiune maximă mai mică în zona sacrală. în al doilea rând, unele valori ale PP au depăşit limita maximă (100 mmHg) a sistemului de măsurare, dar valorile presiunii mai mari de peste 100 mmHg nu sunt relevante, întrucât circulaţia capilară a fost deja oprită atunci când presiunea a depăşit $10 \mathrm{kPa}$ (76 mmHg) [12]. Sunt necesare investigaţii suplimentare pentru a explora în continuare corelaţia dintre eficienţa saltelei din blană de oaie şi tehnologia de tăbăcire a blănurilor de oaie.

\section{CONCLUZII}

Pacienţii trebuie să fie atenţionaţi că unghiul de înclinaţie nu trebuie să fie menţinut prea mult timp la o valoare mai mare de $60^{\circ}$, deoarece în acest unghi presiunea este încă ridicată în zona sacrală şi în zona feselor. S-a evaluat cantitativ gradul de reducere a presiunii la utilizarea saltelei din blană de oaie la fiecare unghi de înclinaţie şi s-a constatat că este superioară în comparaţie cu salteaua de spital obişnuită la majoritatea unghiurilor de înclinaţie. Cu toate acestea, sunt necesare îmbunătăţiri 
was still required, such as a 3D structure was introduced to lower the higher pressure at the sacrum area.

\section{Acknowledgement}

The author would like to thank the financial support from National Science and technology support program (2014BAE02B02) and Funding of Sichuan University (2014SCU11029). suplimentare ale SSM în ceea ce priveşte forma, cum ar fi introducerea unei structuri 3D pentru a reduce presiunea ridicată în zona sacrală.

Mulţumiri

Autorul doreşte să mulţumească pentru sprijin financiar Programului Naţional de Sprijin pentru Ştiinţă şi Tehnologie (2014BAE02B02) şi Universităţii Sichuan (2014SCU11029).

\section{REFERENCES}

1. Aronovitch, S.A., Wilber, M., Slezak, S., Martin, T., Utter, D., Ostomy Wound Manag, 1999, 45, 34-40.

2. Cherry, G.W., Ryan, T.J., Pathophysiolgy, In: Parish, L.C., Witkowski, J.A., Crissey, J.T. (eds.) The Decubitus Ulcer in Clinical Practice, Berlin: Springer, 33-43, 1997.

3. Defloor, T., Appl Nurs Res, 2000, A, 13, 2-11.

4. Nijs, N., Toppets, A., Defloor, T., Bernaerts, K., Milisen, K., Van Den Berghe, G., J Clin Nurs, 2009, 18, 1258-1266.

5. Klaesner, J.W., Hastings, M.L., Zou, D.Q., Lewis, C., Mueller, M.J., Arch Phys Med Rehabil, 2002, 83, 1796-801.

6. De Simon, S., La Penna, A., Napoletano, M., Uccioli, L., Diabetologia, 2002, 45, A337.

7. McInnes, E., Jammali-Blasi, A., Bell-Syer, S.E.M., Dumville, J. C., Cullum, N., Cochrane Database Syst Rev, $2011,4$.

8. McGowan, S.M.K., Jolley, D., Wright, R., Primary Intention, 2000, 8, 1-8.

9. Jolley, D.J., Wright, R., McGowan, S., Hickey, M.B., Campbell, D.A., Sinclair, R.D., Montgomery, K.C., Med J Aust, 2004, 180, 324-327.

10. Kemp, M.G., Kopanke, D., Tordecilla, L., Fogg, L., Shott, S., Matthiesen, V., Johnson, B., Res Nurs Health, 1993, 16, 8996.

11. Jin, Z., Qiuyue, T., Bo, X., Wuyong, C., J Soc Leath Tech Ch, 2013, 97, 172-175.

12. Basler, A., Abderhaldens Hamduch, 1927, 5, 559-557.

Article received/Data primirii articolului: 25.03.2015

Accepted/Acceptat la data: 29.05.2015 